\title{
Relationship of Body Mass Index with Dental Caries among Children attending Pediatric Dental Department in an Institute
}

\author{
Parajeeta Dikshit, ${ }^{1}$ Senchhema Limbu, ${ }^{1}$ Rosina Bhattarai ${ }^{2}$ \\ 'Department of Pedodontics, Kantipur Dental College, Basundhara, Kathmandu, Nepal, ${ }^{2}$ Department of Community \\ Dentistry, Kantipur Dental College, Basundhara, Kathmandu, Nepal.
}

\section{ABSTRACT}

Introduction: Oral health, the mirror of general well being, is altered by many mediators like infection, chronic inflammation, and genetic predisposition. Apart from these mediators, nutrition has been postulated as an alternative mediator. The present dietary pattern among children is contributing to childhood overweight as well as increasing the risk for developing dental caries. The food habits contributing to dental caries as well as obesity are similar. Undernutrition has also shown to be associated with the dental caries. The study was conducted to investigate the relationship of body mass index to dental caries.

Methods: A cross sectional clinical study was conducted on 7 to 12 year old children, studying in public schools, visiting the Department of Pediatric Dentistry for a routine dental check up. The study evaluated the nutritional status by calculating the body mass index using the formula BMI= Weight $(\mathrm{kg}) /$ Height $^{2}\left(\mathrm{~m}^{2}\right)$. Then their Body Mass Index was correlated with the Dental caries status using WHO criteria for decayed, missing and filled teeth index. Data analysis was done by SPSS 20 software program.

Results: Total of 251 children between 7 to 12 years were evaluated. The mean age of the participants was 9.12 years. No statistically significant result was found on comparing the nutritional status to dental caries $(\mathrm{P}=0.43)$. A statistically significant difference though was found on comparing dental caries status among gender $(\mathrm{P}=0.021)$ as well different age groups $(\mathrm{P}=0.031)$.

Conclusions: The study showed the presence of more normal and underweight children but there was no statistically significant association between body mass index and decayed, missing and filled teeth index.

Keywords: Body Mass Index; children; dental caries.

\section{INTRODUCTION}

Good oral health is a gateway to healthy individual, it improves the chewing ability for adequate nutrition, physical growth and learning. ${ }^{1}$ The world today faces two kinds of malnutrition, one associated with nutritional deficiency and the other with dietary excess. The Body Mass Index (BMI), according to age and gender, helps in assessing the child's nutritional status. ${ }^{2}$ Malnutrition is a major public health problem in low income countries including Nepal. Ghosh et $\mathrm{al}^{3}$ found a high prevalence of undernutrition in Nepalese children, compared to the international standards.

Many researches have shown a positive relation between obesity and dental caries as both are clearly related

Correspondence: Dr. Parajeeta Dikshit, Department of Pedodontics, Kantipur Dental College, Basundhara, Kathmandu, Nepal. Email: pardix9@gmail.com, Phone: +977-9849695261. 
Dikshit et al. Relationship of Body Mass Index with Dental Caries among Children attending Pediatric Dental Department in an Institute

to the consumption of fermentable carbohydrates, assuming that they would correlate well. ${ }^{4,5}$

This present study was conducted with the objective to determine the relationship of nutritional status using Body mass index with dental caries among children in a selected Nepalese community.

\section{METHODS}

This cross sectional observational study was conducted in the Pediatric Dental department (Pedodontics) of Kantipur Dental College teaching hospital and research centre, Kathmandu, Nepal. The study sample consisted of children between 7 to 12 years studying in public schools, visiting the hospital for their dental treatment from June 2017 to August 2017 after approval from the Institutional Research Committee. Dental and physical examinations of the children were conducted after obtaining consent from the parents and guardians. The inclusion criteria included: children between 7-12 years of age studying in public schools. Whereas exclusion criteria comprised of children with dentofacial deformities or any syndrome, medically and physically compromised patient or on long term medication, children whose consent could not be obtained, children undergoing orthodontic treatment, children with multiple missing teeth and children studying in private schools.

Total of 251 patients were enrolled in the study and the sample size was calculated by using the formula:

Sample size $n=1+\frac{\frac{Z^{2} \times P(1-P)}{\frac{e^{2}}{Z^{2} \times P(1-P)}}}{Z^{2} N}$

$e=5 \%$, Confidence level $=95 \%, N=715, P=0.5$ Anthropometric measurements were taken before dental examination. The Dental examination was performed using a mouth mirror and a blunt probe under clinical lighting, before and after drying the tooth surface. The dental caries was recorded using the WHO standard criteria for dental caries diagnosis, namely the decayed, missing and filled teeth (dmft/DMFT) index. The nutritional status was determined by calculation of the body mass index using the formula $\mathrm{BMI}=$ Weight $(\mathrm{kg}) / \mathrm{Height}^{2}\left(\mathrm{~m}^{2}\right)$ in kilograms and meters respectively. The total obtained was classified according to the International Classification into underweight, overweight and obesity according to $\mathrm{BMI}$ by $\mathrm{WHO}$.

The findings were filled in the proforma developed for this study and data was entered in Microsoft Excel. The result obtained was analyzed using SPSS version 20. The dmft/DMFT and its association with BMI were evaluated. The significant level was set to be $<0.05$. Independent Sample t-test, Chi-square test and ANOVA test were used to correlate the comparative qualitative data.

\section{RESULTS}

Of the 251 children with the mean age of 9.12 years, $118(47 \%)$ were female and 133 (53\%) were male participants (Figure 1). The distribution of BMI showed that $181(72.1 \%)$ children were of normal weight, $66(26.3 \%)$ underweight and only $4(1.6 \%)$ were overweight. None of the children fell in the obese category (Figure 2). The mean DMFT of the participants was 4.29. The I Independent sample t-test was applied and it showed there was statistically significant difference between DMFT and gender (Figure 1). ANOVA test showed a statistical significance between age of the participants and DMFT (Table 1). There was no statistical significant difference on comparing BMI with Mean DMFT using one way ANOVA test (Table 2) or in age wise comparison of BMI and DMFT using the Chi Square test (Table 3).
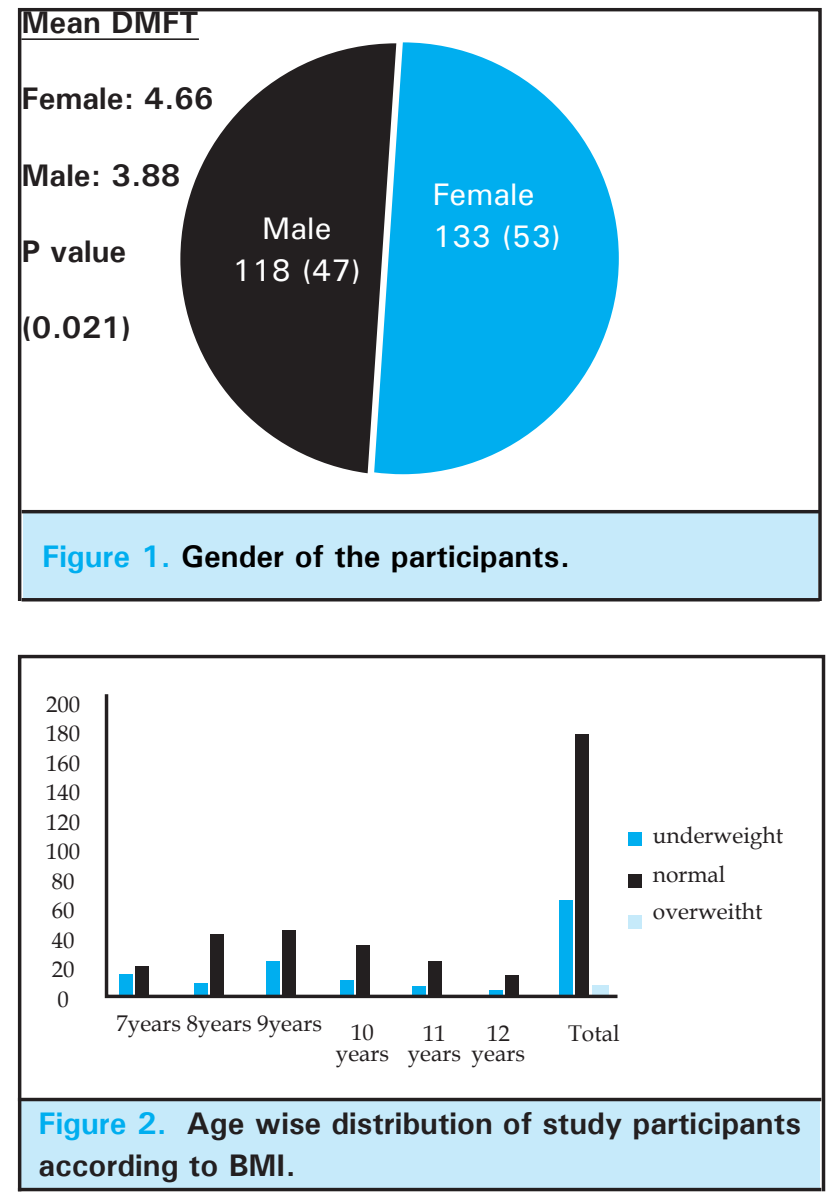
Dikshit et al. Relationship of Body Mass Index with Dental Caries among Children attending Pediatric Dental Department in an Institute

\begin{tabular}{|lclll|}
\hline \multicolumn{5}{|c|}{ Table 1. Age of participants and DMFT. } \\
\hline Age & Frequency & $\begin{array}{l}\text { M e a } \mathbf{n} \\
\text { DMFT }\end{array}$ & $\begin{array}{l}\text { Standard } \\
\text { deviation }\end{array}$ & value \\
7 years & 35 & 3.49 & 2.13 & \\
8 years & 53 & 4.75 & 2.71 & 0.031 \\
9 years & 70 & 4.77 & 3.00 & \\
10 years & 47 & 4.43 & 2.74 & \\
11 years & 31 & 3.84 & 2.47 & \\
12 years & 15 & 2.87 & 1.50 & \\
Total & 251 & 4.29 & 2.69 & \\
\hline
\end{tabular}

\begin{tabular}{|lllll|}
\hline \multicolumn{4}{|l|}{ Table 2. BMI Along With Mean DMFT. } \\
\hline BMI & Frequency & $\begin{array}{l}\text { M e a } \mathbf{n} \\
\text { DMFT }\end{array}$ & $\begin{array}{l}\text { Standard } \\
\text { deviation }\end{array}$ & P value \\
Underweight & 66 & 4.56 & 3.05 & \\
Normal & 181 & 4.23 & 2.55 & \\
Overweight & 4 & 3.00 & 2.44 & 0.432 \\
Total & 251 & 4.29 & 2.69 & \\
\hline
\end{tabular}

\begin{tabular}{|c|c|c|c|c|c|c|c|c|}
\hline \multirow[b]{2}{*}{ Age } & \multicolumn{6}{|c|}{ BMI classification } & \multirow[b]{2}{*}{ Total } & \multirow[b]{2}{*}{$P$ value } \\
\hline & Underweight & $\begin{array}{l}\text { Mean } \\
\text { DMFT }\end{array}$ & Normal & $\begin{array}{l}\text { Mean } \\
\text { DMFT }\end{array}$ & Overweight & $\begin{array}{l}\text { Mean } \\
\text { DMFT }\end{array}$ & & \\
\hline 7 years & 15 & 3.20 & 20 & 3.70 & 1 & 0 & 35 & \\
\hline 8 years & 9 & 6.00 & 43 & 4.58 & 1 & 1.0 & 53 & \\
\hline 9 years & 23 & 5.39 & 45 & 4.56 & 2 & 2.50 & 70 & \\
\hline 10 years & 11 & 4.82 & 35 & 4.26 & 1 & 6.00 & 47 & \\
\hline 11 years & 7 & 2.71 & 24 & 4.17 & 0 & 0 & 31 & \\
\hline 12 years & 1 & 3.00 & 14 & 2.86 & 0 & 0 & 15 & 0.15 \\
\hline Total & 66 & 4.56 & 181 & 4.23 & 4 & 2.44 & 251 & \\
\hline
\end{tabular}

\section{DISCUSSION}

Although dental caries has seen a global decline in general population, but the caries prevalence in children has not shown a significant decline. ${ }^{6}$ In the present study only $9.6 \%$ children were caries free. This is considered to be on the higher range and could be because in Nepal, most of the parents bring their child to the dentist only on presence of symptoms. Most of the children of all the ages were in the normal weight category with only few overweight, $26 \%$ children were found to be in the underweight category. This may be attributed to the fact that the children belonged to low and middle income families. Malnutrition among young children is a major concern in low income countries like Nepal where under nutrition remains one of the primary causes of ill health. Nepal Demographic and Health
Survey (NDHS 2011) revealed that young children are suffering from high rates of chronic malnutrition. ${ }^{7}$

In this study females had a significantly higher mean DMFT value than males, which coincides with the findings of Juthamas et $\mathrm{al}^{8}$, and was in contrast to that by Hiremath et $\mathrm{al}^{9}$ while Obafunke el $\mathrm{al}^{10}$ found it equal in both genders. Children of age 8, 9 and 10 years had more caries than other age groups which could be because of the more teeth in the pre-shedding period that have been exposed to oral condition. The children in younger ages have recently erupted permanent first molars and the ones in age 11 and 12 have erupting or just erupted premolars.

There are controversial results documented regarding the relationship between the nutritional status and the 
Dikshit et al. Relationship of Body Mass Index with Dental Caries among Children attending Pediatric Dental Department in an Institute

occurrence of dental caries in children. Some reports claim that being overweight is linked to dental caries, which could be attributed to the fact that overweight or obesity occurs due to consumption of food and food habits closely related to those causing dental caries like refined carbohydrate, sweets as frequent in between meal snacking. However a systematic review conducted by Alexandre et $\mathrm{al}^{11}$ did not find sufficient evidence regarding the association between obesity and dental caries. Dental caries has also shown to be linked to children who are underweight. ${ }^{6,8}$

No statistically significant relation of DMFT with various $\mathrm{BMI}$ categories as well as on comparison of the DMFT with age wise BMI distribution were observed in our study. Similar findings have been reported by many authors. . $^{5,10,12}$

The studies that have described a positive relation of obesity with dental caries have attributed the common causes like consumption of high carbohydrate containing food as the cause of obesity as well as dental caries. ${ }^{11}$ There were no children belonging to obese category so the relation could not be established in the present study. Whereas other authors have stated that underweight children have acute or chronic nutritional state that lead to developmental defects in the teeth causing dental caries. ${ }^{6,8,13}$ Furthermore dental caries during the developmental years may have led to malnutrition causing a loss of body weight. Acs et $\mathrm{al}^{14}$ found that children with early childhood caries had a significantly less body weight which was less than
$80 \%$ of their ideal weight. Later they suggested that the intake of high carbohydrates predisposed to early childhood caries initially, causing an increase in weights, but progression of caries caused pain, infection, altered eating and sleeping patterns causing a decline in body weight. Dental caries can be caused due to unhealthy nutritional factors and the disease can as well be the source of undernutrtion in children.

The principal limitation of the study relates to the sample size that was drawn from a specific population. Therefore, these results cannot be generalized to the entire population.

\section{CONCLUSIONS}

No significant association was found between DMFT and $\mathrm{BMI}$ in the studied population. A larger study where all strata of BMI may be well represented is recommended. The need for continuous caries preventive educational programs which must include adequate diet is important especially in communities where dental visits are usually symptomatic.

\section{ACKNOWLEDGEMENTS}

The authors wish to acknowledge all the participants as well as staff of Department of Pediatric Dentistry, Kantipur Dental College.

Conflict of Interest: None.

\section{REFERENCES}

1. Sharma K, Kaur H. Oral health in relation to nutritional status, age and sex among 14-18 years children of Naraingarh, Haryana. Braz Dent Sci. 2015;18(3):68-76. [Full Text]

2. Santha B, Sudheer H, Saxena V, Jain M, Tiwari V. The impact of Body Mass Index on Oral Hygiene Practices of Adolescents in Bhopal City, India. Journal of the College of Physicians and Surgeons Pakistan. 2016;26(2):125-9. [Full Text]

3. Ghosh A, Adhikari P, Chowdhury SD, Ghosh T. Prevalence of undernutrition in Nepalese children. Ann Hum Biol. 2009;36(1):38-45. [uㅏbMed | DOI | Full Text]

4. Alswata K, Mohameda WS, Wahabb AM, Aboelilb AA. The association between body mass index and dental caries: cross-sectional study. J Clin Med Res. 2016;8(2):147-52. [PubMed | Full Text]

5. Sharma S, Shukla A, Parashar P, Ahmad S, Bansal R, Varshney AM, Dharmender. Association between dental caries and BMI-for age with sugar consumption among school children. Asian Pac J. Health Sci. 2014;1(4S):58-62. [Full Text]
6. Chatterjee M, Bandyopadhyay AR. A study on nutritional status and dental caries in permanent teeth among school going girl of Bengalee population, India. Advances in Anthropology. 2012;2(3):112-6. [Full Text]

7. Paudel S, Pradhan PMS, Limbu NPM, Shrestha SM, Pandeya P, Regmi B. Aryal B. Nutrition status of young children in periphery of Lalitpur Sub-Metropolitan city in Nepal. JCMS Nepal. 2017;13(3):330-4. [Full Text]

8. Lueangpiansamut J, Chatrchaiwiwatana S, Muktabhant B, Inthalohit W. Relationship between dental caries status, nutritional status, snack foods, and sugar-sweetened beverages consumption among primary schoolchildren grade 4-6 in Nongbua Khamsaen School, Na Klang district, Nongbua Lampoo Province, Thailand. J Med Assoc Thai. 2012;95(8):1090-7. [PubMed]

9. Hiremath A, Murugaboopathy V, Ankola AV, Hebbal M, Mohandoss S, Pastay P. Prevalence of dental caries among primary school children of India - A Cross-Sectional Study. J Clin Diagn Res. 2016;10(10):47-50. [Full Text] 
10. Denloye O, Popoola B, Ifesanya J. Association between dental caries and body mass index in 12 -15 year old private school children in Ibadan, Nigeria. Pediatric Dental Journal. 2016;26(1):28-33. [DOI]

11. Silva AER, Menezes AMB, Demarco FF, Vargas-Ferreira F, Peres MA. Obesity and dental caries: systematic review. Rev Saúde Pública. 2013;47(4):799-812. [Full Text]
12. Parkar SM, Chokshi M. Exploring the association between dental caries and body mass index in public school children of Ahmedabad city, Gujarat. SRM J Res Dent Sci. 2013;4(3):101-5. [Full Text]

13. Xavier A, Bastos RDA, Arakawa AM, Caldana MDL, Bastos JRM. Correlation between dental caries and nutritional status: preschool children in a Brazilian municipality. Rev Odontol UNESP. 2013;42(5):378-83. [Full Text]

14. Acs G, Shulman R, Ng M, Chussid S. The effect of dental rehabilitation on the body weight of children with early childhood caries. Pediatr Dent. 1999;21:109-1. [Full Text] 